\title{
BMJ Open Factors of importance for reducing fatigue in persons with rheumatoid arthritis: a qualitative interview study
}

\author{
Caroline Feldthusen, ${ }^{1,2}$ Kaisa Mannerkorpi ${ }^{1,2}$
}

To cite: Feldthusen C, Mannerkorpi K. Factors of importance for reducing fatigue in persons with rheumatoid arthritis: a qualitative interview study. BMJ Open 2019;9:e028719. doi:10.1136/ bmjopen-2018-028719

- Prepublication history for this paper is available online. To view these files please visit the journal online (http://dx.doi. org/10.1136/bmjopen-2018028719).

Received 20 December 2018 Revised 15 March 2019 Accepted 9 May 2019

\section{Check for updates}

(C) Author(s) (or their employer(s)) 2019. Re-use permitted under CC BY-NC. No commercial re-use. See rights and permissions. Published by BMJ.

${ }^{1}$ Department of Health and Rehabilitation, Unit of Physiotherapy, University of Gothenburg Institute of Neuroscience and Physiology, Goteborg, Sweden

${ }^{2}$ University of Gothenburg Center for Person-Centred Care, Sahlgrenska Academy, University of Gothenburg, Gothenburg, Sweden

Correspondence to Dr Caroline Feldthusen; caroline.feldthusen@gu.se

\section{ABSTRACT}

Objective Physical activity plays an important role in the treatment of persons with rheumatoid arthritis (RA) and is the non-pharmacological intervention with the strongest evidence to reduce fatigue. However, physical activity can be challenging for persons who are fatigued. The aim of this study was to investigate factors of importance for reducing fatigue in persons with $\mathrm{RA}$.

Design This is a qualitative interview study based on semistructured, indepth individual interviews. Interviews were analysed using qualitative content analysis. Participants Participants were 12 people with RA recruited from a previous randomised controlled trial of a person-centred treatment model focusing on healthenhancing physical activity and daily balance to lessen fatigue in persons with RA.

Setting Interviews were conducted in a hospital setting. Results The analysis resulted in one theme: an intellectual and embodied understanding that sustainable physical activity is important to handle fatigue. This included five categories describing barriers and facilitating factors for sustainable physical activity: mentally overcoming the fatigue in order to be active, making exercise easy, reaching for balance, receiving support to be physically active and dealing with $R A$ disease to be physically active.

Conclusion The participants in this study expressed that physical activity was important in handling fatigue, but also that this insight could only come from personal experience. The use of a person-centred ethic in physiotherapy coaching for patients with fatigue appears to promote sustainable physical activity behaviours by facilitating patients' resources to overcome barriers to physical activity.

\section{INTRODUCTION}

Fatigue is a prominent symptom in persons with rheumatoid arthritis (RA) and one which has a considerable impact on daily life. ${ }^{1}$ Despite improvement in pharmacological treatment of RA in recent decades, ${ }^{2}$ over $80 \%$ of persons with RA report that they suffer from fatigue, and about $40 \%$ describe severe fatigue. ${ }^{34}$ Fatigue in RA has traditionally been associated with inflammation, but modern pharmacological treatment has only a small effect on fatigue. ${ }^{45}$ Stronger evidence

\section{Strengths and limitations of this study}

This study used a well-established qualitative method to better understand the perspectives of people with fatigue in rheumatoid arthritis.

- Participants had experiences of physical activity on different levels.

- Participants had reflected on their fatigue and how to handle it, which gave depth and nuances in their experiences.

- Participants were relatively homogeneous in their age, which may limit the generalisability of the results.

has been found for associations between fatigue and pain, disability/physical function and depression/depressive mood. ${ }^{467}$

From the patient's perspective, fatigue is one of the most important issues in RA. ${ }^{1}$ In qualitative studies, persons with RA describe how fatigue causes considerable consequences that negatively affect all aspects of life. ${ }^{8-10}$ Also described is an increased amount of time required for rest and sleep, resulting in feelings of imbalance in life due to less time being available to accomplish other things. ${ }^{9}$

Besides pharmacological treatment, physical activity is an important part of RA treatment $^{11}$ and has been found to be the non-pharmacological intervention with the strongest evidence to reduce fatigue. ${ }^{4} 712$ However, physical activity can be challenging for persons who suffer from fatigue, ${ }^{11} 13$ and people with RA are known to be less physically active than the general population. ${ }^{14} 15$ Pain and fatigue are the most frequently mentioned barriers to physical activity among people with $\mathrm{RA}$, together with more generic barriers such as lack of time and costs. ${ }^{11}$ The complexity and individual impact of fatigue ${ }^{1316}$ suggest that standard interventions to enhance physical activity are insufficient, ${ }^{17}$ and brief advice has been found to only have a modest role to play in long-term efforts to improve levels of physical activity in this population. ${ }^{18}$ 
A person-centred approach is anticipated to strengthen a person's confidence and resources, ${ }^{19}$ which will allow persons with RA to enhance their physical activity and improve the balance of their activities in order to control fatigue and symptoms associated with fatigue. ${ }^{20}$ The ethic of person-centredness views each person through a biological, psychological and social perspective, ${ }^{1921-23}$ where the patient is seen as a person with reasons, will, feelings and needs. ${ }^{19}$ Being a person includes the capacity of being capable, ${ }^{24}$ including the capacity to enhance one's own health and to be an active partner in the rehabilitation process. ${ }^{21}$ A person-centred approach commonly starts with partnership building based on the person's narrative, and includes sharing of information, shared deliberation, and shared decision-making and documentation. ${ }^{19}$ To address fatigue in persons with RA by enhancing physical activity and balance in life, a person-centred treatment model emanating from each person's life situation, preferences and resources has shown positive effects on fatigue, physical function and health. ${ }^{20}$

The purpose of this qualitative interview study was to investigate factors of importance for reducing fatigue in persons with RA.

\section{METHODS}

\section{Study design}

We conducted a qualitative interview study with semistructured indepth individual interviews ${ }^{25}$ analysed using qualitative content analysis, ${ }^{26}$ a methodology with a long history in nursing studies. ${ }^{27}$

\section{Participants}

Persons diagnosed with $\mathrm{RA}^{28}{ }^{29}$ were recruited from a previous randomised controlled trial $(\mathrm{n}=70)$ evaluating the effects of a person-centred treatment model to reduce fatigue. The intervention focused on health-enhancing physical activity and balancing activities in daily life, and was formed jointly by the participant and physiotherapist according to each participant's life situation. ${ }^{20}$ The goal of the intervention was to devise a mutually agreed self-care plan that guided the participant in effectively managing their own fatigue over time. The previous RCT study ${ }^{20}$ showed significant effects on fatigue in the intervention group compared with the control group. The participants in the intervention group were expected to possess important experiences of how to reduce fatigue by a non-pharmacological intervention that we wanted to elucidate. Therefore, this present interview study was planned, and 2.5 years after completing participation in the RCT study a letter with written information and an invitation to participate was sent to all persons in the intervention group $(n=36)$. To increase the number of participants, a second letter of invitation was sent after 2 months to the persons not responding to the first letter. Twelve participants $(30 \%)$ agreed to participate.

\section{Data collection}

An independent health professional (physiotherapist) who was not involved in the previous intervention

\section{Box 1 Interview guide}

A couple of years ago you participated in a research study in which you together with a physiotherapist developed a treatment plan to lessen your fatigue.

What did you do to lessen your fatigue?

What worked well?

What did not work?

- Can you tell me about how you experienced your treatment plan?

Could you please tell me how your fatigue has been influenced since after the study?

What do you do today to handle your fatigue?

What problems have you encountered?

Could you please tell me about your experiences of fatigue in general?

- What do you experience is important to handle fatigue?

What can facilitate?

Are there things you cannot influence?

conducted the interviews in a hospital setting. An interview guide was developed, including open-ended questions about what the participants perceived as helping to diminish fatigue and how these strategies were incorporated in daily life. The interview guide covered questions regarding own strategies used during the intervention, strategies used today and general view on handling fatigue in RA (box 1). The participants shared their concrete, lived experiences based on their life-world perspective and understood from a situational context. A pilot interview was conducted and did not result in any changes to the interview guide. Each interview lasted approximately 20-50 min.

\section{Data analyses}

Interviews were audio-recorded and transcribed verbatim by the first author (CF), a physiotherapist with knowledge of person-centred care. The transcribed interviews were then analysed with qualitative content analysis. ${ }^{30}$ Qualitative content analysis includes interpretations of the concrete content close to the text, as well as deeper interpretations of its underlying latent meaning. ${ }^{30} 31$ After reading the transcripts, meaning units answering the aim of the study were derived from the texts and abstracted without being separated from the context. From the abstracted meaning units, subcategories and categories and a theme were formed by moving back and forth between the whole text and its parts. The deriving and abstracting of meaning units were performed by the first author and discussed with the last author (KM), a senior researcher and physiotherapist. The subcategories and categories were formed together by the first and last author and discussed until consensus was achieved.

\section{Patient and public involvement}

A research partner from the Swedish Rheumatism Association participated in the development of the person-centred treatment model. In the present interview study, a pilot interview was performed. A person with RA, own experience of fatigue and recently completed 


\begin{tabular}{ll} 
Table 1 Participants & \\
\hline Participant & Gender (female/male) \\
\hline A & Female \\
B & Female \\
C & Male \\
D & Female \\
E & Male \\
F & Female \\
G & Female \\
H & Female \\
I & Female \\
J & Female \\
K & Female \\
L & Female \\
\hline
\end{tabular}

rehabilitation according to person-centred ethics was recruited and asked to comment on the relevance of the interview guide and the setting.

\section{RESULTS}

Twelve participants agreed to participate in the interview study, comprising 10 women and 2 men (table 1 ) with a mean age of 63 years, ranging from 50 to 68 years, and a mean disease duration of 19 years, ranging from 7 to 32 years. Compared with the eligible participants who did not agree to participate, the participants in the interview study were older (63 years compared with 56 years), and at baseline less fatigued rated on a Visual Analogue Scale ${ }^{32}$ (VAS fatigue $(0-100 \mathrm{~mm}) 65 \mathrm{~mm}$ compared with $72 \mathrm{~mm}$ ). There was no difference in physical activity level measured with Leisure Time Physical Activity Index ${ }^{33}$ between the persons who agreed to participate (2.8 hours/week, range $0-17)$ and the persons who did not (2.6hours/ week, range 2-16), and there was an equal improvement in both groups during the intervention regarding VAS fatigue (mean (SD) decrease 24 (27.4) $\mathrm{mm}$ compared with $25(27.8) \mathrm{mm}$ ) and physical activity level (mean (SD) increase 1.6 (3.6) hours/week compared with 1.2 (3.4) hours /week).

The interviews were conducted over a 4-month period (December-March). One interview was conducted over the telephone lasting $20 \mathrm{~min}$, and the others at the physiotherapy premises at Sahlgrenska University Hospital, Gothenburg, Sweden, lasting $40-50 \mathrm{~min}$. The analysis is presented in one theme and five categories with associated subcategories (table 2). The subcategories were supported by quotes. The character within bracket after each quote refers to the specific participant (table 1).

An intellectual and embodied understanding that sustainable physical activity is important to handle fatigue

This theme outlines the experience that sustainable physical activity enhances energy and forms the basis of
Table 2 Theme and categories with associated subcategories

\section{Theme \\ An intellectual and embodied understanding that sustainable physical activity is important to handle fatigue.}

\begin{tabular}{|c|c|}
\hline Category & Subcategory \\
\hline $\begin{array}{l}\text { Mentally } \\
\text { overcoming the } \\
\text { fatigue in order } \\
\text { to be active. }\end{array}$ & $\begin{array}{l}\text { Overcoming the fatigue requires hard work. } \\
\text { Having a positive attitude. } \\
\text { Diverting the fatigue. } \\
\text { Earlier experiences and self-image } \\
\text { influence physical activity. }\end{array}$ \\
\hline $\begin{array}{l}\text { Making exercise } \\
\text { easy. }\end{array}$ & $\begin{array}{l}\text { Incorporating physical activity in one's } \\
\text { everyday routine. } \\
\text { Physical activity in my own way. } \\
\text { Having a plan for physical activity. }\end{array}$ \\
\hline $\begin{array}{l}\text { Reaching for } \\
\text { balance. }\end{array}$ & $\begin{array}{l}\text { Handling demands. } \\
\text { Allowing for recovery. } \\
\text { Mastering time. }\end{array}$ \\
\hline $\begin{array}{l}\text { Receiving } \\
\text { support to } \\
\text { be physically } \\
\text { active. }\end{array}$ & $\begin{array}{l}\text { Receiving professional support. } \\
\text { Support to increase motivation. } \\
\text { Social support and understanding. }\end{array}$ \\
\hline $\begin{array}{l}\text { Dealing with the } \\
\text { RA disease to } \\
\text { be physically } \\
\text { active. }\end{array}$ & $\begin{array}{l}\text { Living with the symptoms and fluctuations } \\
\text { of the disease. } \\
\text { Strengthening the ability to manage the } \\
\text { disease. } \\
\text { Making adjustments and creating good } \\
\text { conditions. }\end{array}$ \\
\hline
\end{tabular}

RA, rheumatoid arthritis.

handling fatigue. To reach this understanding required both intellectual reflection and embodied experiences.

The five categories describe barriers as well as facilitating factors for sustainable physical activity, and include physical, psychological, social and environmental aspects.

\section{Mentally overcoming the fatigue in order to be active}

Overcoming the fatigue requires hard work

The participants described how they had to work hard in order to mentally overcome the fatigue and be active. The fatigue made it hard for them to get going and translate ideas into action, and they expressed feeling lazy. Being active and overcoming their fatigue were experienced as depending on their own will, their ability to be persistent and their willingness to take responsibility for their exercise/activity instead of blaming others.

I've figured out that if I, when I come home from work, if I sit down for onehour to drink coffee... don't do that because your body stiffens and then it's all over. Instead you rather pace your tempo but carry on, because once you've sat down or relaxed it's hard to get going again. (E) 


\section{Having a positive attitude}

The participants said that to overcome the fatigue, they had to accept the fatigue, live with it, and do their best to maintain their mood, see things positively and use humour to keep the fatigue at bay instead of whining and being grumpy. They also believed they had to acknowledge what they had done and be content with that instead of focusing on the things they had not been able to do.

You have to take it naturally that this is the way it is, try to make the best of it and keep your mood up. At least try. Because if you just walk around feeling sorry for yourself then you get tired, I mean then you're not only tired but you're tired and unhappy, and that's something even worse. (J)

\section{Diverting the fatigue}

The participants described building up mental strategies in order to repress their fatigue. Being in the present and not becoming stressed about things that remained to be done was expressed as a factor that could distract the participants from their fatigue and enhance their physical activity. Another strategy was to prioritise amusing things and things that made them feel good.

That's the weirdest thing. It's like you're just 'Oh, forget it, I'm really tired', when it's time to go to choir. 'No, I will go! It'll probably get better'. And then you come home and you're on a high instead. (D)

\section{Earlier experiences and self-image influence physical activity}

Earlier experiences of physical activity as well as an active lifestyle were described by the participants as having an effect on the ability to exercise despite fatigue. Some participants enjoyed exercise and had confidence in how and where to exercise, while others labelled themselves as unwilling to exercise and felt insecure about going to the gym. The participants' images of themselves and expectations of life influenced their views on exercise and overcoming the fatigue.

I know that many of my friends with rheumatism say 'No, I can't go out before eleven o'clock, I'm too tired in the morning'. I don't want to get like that, I don't want to. I say 'I can come at quarter to ten, nine if that's OK'. (D)

\section{Making exercise easy}

Incorporating physical activity in one's everyday routine

According to the participants, being able to exercise when fatigued required that the exercise was not too large an obstacle to overcome. Continuity in physical activity with a structure fitting into their normal routine was important, as well as interlinking physical activity as a natural part of everyday life.

I did this - I went out for a walk during lunch. I could do that because we had an hour for lunch, so I spent half an hour eating lunch and then I went for a walk. Not everyone can do that, but for me it worked out fine. (B)

\section{Physical activity in my own way}

The participants expressed the importance of finding a physical activity or exercise that worked for them. This included finding their own pace and allowing themselves to adjust the physical activity according to daily fitness or external circumstances such as weather conditions or social obligations. Contextual factors also mattered, such as the exercise being close to home or easy to get to, and fitting into their schedule and financial situation. Amusing activities or something to look forward to increased the motivation to accomplish physical activity, and a larger effort could be made. Experiencing health benefits also made it easier for them to push themselves or to accomplish a valued physical task.

I think it's so boring to exercise, for the simple reason that you sit on an exercise bike and cycle for an hour and then you get off and you're in the exact same position as when you started. Or lift a weight or push something and achieve nothing. On the other hand I think it's great fun to work in the garden, to do physical, heavy work. All my life I've thought athletics and sports are silly. But I have no problem getting exhausted and sweaty from building, digging, and so on. (C)

\section{Having a plan for physical activity}

The participants described the benefits of making a plan or schedule for physical activity. Knowing in advance what to do and having a plan for overcoming obstacles to physical activity increased their motivation to get going. In addition, having a goal to strive towards enhanced their accomplishment of physical activity.

If I know that I'm going to a class, and it's booked, and I get to leave work early. I'd never skip that sort of thing. It's almost like it's part of work, and you can't get away even if you have a bad day. Otherwise, when the fatigue is attacking you it's really easy to think 'No, I'll do it another day'. (L)

\section{Reaching for balance}

Handling demands

The participants described struggling with their obligation to fulfil what was expected of them while still balancing their energy in order to be able to take care of themselves and to exercise. Work and social demands limited their time and energy, and they found it hard to have energy left for exercise after an 8-hour workday. The participants expressed having to accept that the fatigue made them lower their demands, and described handling the fatigue by prioritising and receiving help.

Every day when I come home from work, I'm really tired. That's just the way it is. And it's hard to 
deal with things, but there are those things you have to do...//...it was this thing about the cooking. Eventually it got so boring that it was hard even to talk about it. I was just angry and whining. But when we started getting meal kits delivered it was more fun, and of course you don't get so tired. (L)

\section{Allowing for recovery}

The participants described that besides physical activity, recovery and allowing themselves to relax were important. They needed to find a balance between activity and rest, and between work and spare time.

It's pretty much about listening. To kind of listen to my body and maybe not just...go on but actually... now I'm tired, now I need to take it a bit easy. Some breaks and such. $(\mathrm{G})$

Sleep was also expressed as important for recovery. Disturbed sleep affected energy and fatigue, but too much sleep increased fatigue instead of leading to recovery. Physical activity was described as entailing a comfortable physical fatigue which enhanced sleep quality.

\section{Mastering time}

The possibility of being in charge of one's own time was expressed as influencing both fatigue and the capability to exercise. Some participants said that the time was not there, but it had to be created and planned for. The opportunity to exercise in working hours was often hard to coordinate. Retirement and the ability to take the day as it comes were a beneficial factor.

I had it good in that I could work from home sometimes one day a week, so that was an advantage. But anyway, it's got a lot better since I retired...//...It's completely wonderful to be able to do what you like. I can't still believe it, that I can really just take the day as it comes...it's totally fantastic. (A)

\section{Receiving support to be physically active \\ Receiving professional support}

The participants expressed the importance of feeling confident in how to exercise while having a rheumatic disease. Professional support was especially important for those unfamiliar with exercise. Having someone who could guide and assist them with specific exercises suited to their life situation and resources, follow up the exercise plan, and evaluate the outcome of exercise were expressed as enhancing their motivation and confidence to exercise. Being listened to and seen as a person was important in the contact with professionals, including being introduced and informed without being told what to do.

Every person surely experiences different things. I believe that. And not everyone's willing to put in the same amount of effort. (F)
Support to increase motivation

Exercising together with a spouse or friend, or in a group, was expressed by the participants as helping them to be physically active. Having something or someone to push them increased their motivation. This could also include making their physical activity visible, for example by a follow-up appointment, by being asked about what they had done, or by using a diary or technical gadgets to monitor their physical activity.

This thing where you write down everything you did, it gave me a boost. Now I have to do this so I can write it down. Yes, and a little proud over myself. (J)

\section{Social support and understanding}

It was also important to receive legitimacy and understanding of the fatigue from their next of kin, not to feel alone and exposed, and to receive help and assistance instead of being nagged. Some participants described it as hard when they had to defend why they could not do things.

My husband is my support in this, during the whole disease he's been there in that he says 'Let's do this together'. He pulls me up and tries to get going again, I mean he feels good about it too. (D)

\section{Dealing with the RA disease to be physically active}

Living with the symptoms and fluctuations of the disease

The participants described how their RA affected their ability to perform physical activity. Pain and functional limitations could be a barrier to the type of physical activity they wanted to perform. The participants described struggling with the unpredictability of the disease activity as well as fatigue.

Even if I can't call it a flare right now, I have a lot of pain. I have a lot of pain in my hips when I walk. And I don't need to walk especially long. And then I have this foot and that can also make me walk wrong so my hips...it hurts a lot. (H)

\section{Strengthening the ability to manage the disease}

The participants described how suffering from RA meant living on the border between healthy and ill, and physical activity constituted an opportunity to control the disease. They described having reached this insight into their own ability and responsibility to influence their well-being by accepting that they had to listen to their body, find their own acceptable and well-functioning activity level, and not give up.

Well, just this to strengthen yourself. Of course it (physical activity) is healthy. So no, despite pain you don't stop, but go on. That's, that's strengthened you. Just the feeling that you can do much, much more than you think. (J) 
Making adjustments and creating good conditions

In order to be able to perform physical activity, the participants described a need to adjust activities and create good settings. Adjusting their physical activity habits when unable to follow their plan was found to be challenging, especially when struggling with fatigue. The participants described benefits of being helped to reflect on their fatigue and find workable solutions.

I cycle a lot, and it causes great pain in my wrists because it's so bumpy. Now I've bought a new bike with shock absorbing handlebars, and that bike's a lot more fun to ride, because I can actually ride it. (L)

\section{DISCUSSION}

The overall theme of this study outlines the importance of physical activity in handling fatigue when living with RA. This is in line with earlier research in which physical activity has been shown to have the strongest evidence to lessen fatigue. ${ }^{4712}$

However, explicit for this study was that the participants expressed that this understanding of the importance of physical activity has to be embodied and each person has to take responsibility for their own priorities. The subcategories describe how the participants embodied this insight and handled obstacles and imbalances in their personal life situation.

Although the participants in this study described having reached the insight that physical activity is important to handle fatigue, they had to struggle to overcome the fatigue in order to engage in physical activity. In studies of physical activity, many individuals drop out of exercise programmes, and those who successfully change behaviour do not necessarily maintain the new behaviour. ${ }^{34}$ To find the proper context and support for each person's needs is described as important for exercise maintenance. ${ }^{34}$ This is in line with the result of this study in which the participants described the importance for themselves in making exercise easy, reaching for balance and receiving support to be physically active.

To overcome their fatigue to be physically active, the participants in the present study described motivation as being central. Motivation depends, among other things, on the perceived outcome benefit and required effort. ${ }^{35}$ Exercise that is self-determined and that satisfies psychological needs is anticipated to strengthen exercise motivation. ${ }^{36}$ The participants in this study described strategies both to lower the effort by planning ahead and making exercise easy, and to increase their motivational drive by doing amusing activities or focusing on positive effects. Earlier experiences, lifestyle habits and self-image were factors influencing physical activity. Patients who engage in regular exercise have earlier been found to experience the same barriers as non-exercising patients, but since the exercisers had experienced the benefits of exercise they were more likely to overcome these barriers and make adaptations that allowed them to exercise. ${ }^{37}$ These embodied experiences of both the benefits of physical activity and how to overcome barriers were highlighted by the participants in this study.

The perception of activities as either achievable or beyond one's current capacities also affects motivation. ${ }^{35}$ Reaching for balance between demands and recovery was important for the participants to be able to engage in sustainable physical activity. The person-centred treatment model that the participants were recruited from ${ }^{20}$ provided an opportunity for them to discuss alternatives for their physical activity, to structure and test a physical activity plan, and to see the plausibility of what they had done. The participants described how support for their reflection helped them to handle personal and social demands, to acknowledge when they had reached an acceptable and sustainable activity level according to their life situation, and to feel satisfied when it was good enough. They expressed a desire to be respected as a person and acknowledged in terms of their whole life and resources, instead of being lectured about how to live their life. This is in line with the ethics of a person-centred approach. ${ }^{19}$

The category receiving support indicated a need for guidance to enhance physical activity, especially for those who felt uncomfortable regarding how to exercise. Lack of knowledge regarding appropriate exercise has earlier been found to be a barrier to exercise among persons with arthritis. ${ }^{11}$ Coaching programmes towards health-enhancing physical activity have been shown to enable increased physical activity, ${ }^{38}$ but have also been shown to involve difficulties in maintaining physical activity after the end of the programme. ${ }^{39}$ The participants in this study described taking their own responsibility and the importance of being in control of themselves as prerequisites for sustainable physical activity.

The impact of RA is a known barrier to exercise, for reasons including a reduced functional ability. ${ }^{11}$ Not being able to continue an earlier well-functioning physical activity routine due to pain and functional limitation made it even harder to adjust when also struggling to overcome the fatigue.

The participants in this study had earlier participated in a person-centred treatment model to lessen fatigue in RA. ${ }^{20}$ As a complex intervention, it includes several components which are not easy to define. ${ }^{40}$ This treatment model was grounded in a person-centred ethic based on participants' resources and used shared deliberation and decision-making to give the participants responsibility for executing the plan. This may have facilitated the participants' insight of acknowledging their own responsibility for their well-being.

An inclusion criterion of the RCT study was severe fatigue ( $>50$ on VAS), and the intervention included reflection on physical activity level and balance among activities in daily life, which ensures the participants own experiences of fatigue as well as experiences on how to handle their fatigue.

The overall theme of this study outlines the importance of physical activity in handling fatigue when living 
with RA. One might wonder if this result may have been influenced by the participation in the earlier RCT study. However, the interviews were carried out 2.5 years after the RCT study, and our experiences from earlier intervention studies show that long-term effects after 1 year seldom remain. ${ }^{41}{ }^{42}$ Still physical activity was found important for the participants.

All qualitative studies assume a given perspective, as the researcher is part of a given context and given period of time. This study was conducted from a physiotherapy perspective searching for more knowledge of factors of importance for reducing fatigue in persons with RA. However, the interview guide was designed to focus on how the interview persons handled fatigue in their life and did not specifically contain questions about physical activity. Nevertheless, the participants raised their own experiences of the importance of physical activity to handle fatigue. The theme and categories of this study add valuable new information to the field, searching for deeper knowledge on factors that influence fatigue in persons with RA. As authors, we are aware that other researchers, assuming other perspectives, might add other pieces of knowledge. We consider that the results of this study are applicable to patients with RA suffering from fatigue, but transferability to other contexts must be judged by the readers.

A strength of this study was that all of the persons who agreed to participate also had the possibility to participate, although one interview was made over telephone. One limitation was that the participants were relatively homogeneous in their age, with 8 of the 12 participants being newly retired. One of the inclusion criteria in the earlier RCT study was being of working age, but some participants had reached retirement age since the end of the study. The participants described being more in control over their time after retirement; being newly retired meant that they were able to recall their earlier working situation and relate it to their new situation. Another limitation was that no current ratings of fatigue or level of physical activity were collected from the participants in this study.

The interviews were analysed with qualitative content analysis, a well-established method that allows for various depths of interpretation. ${ }^{30}$ To increase trustworthiness and credibility, the analysis was performed by both authors.

\section{CONCLUSION}

The participants in this study expressed the importance of physical activity in handling fatigue. To come to this insight, they had to reflect on their barriers and experience how to overcome them. The use of a person-centred ethic in physical activity coaching for patients with fatigue appears to promote sustainable physical activity behaviours by facilitating the patient's resources to overcome barriers to physical activity.
Acknowledgements The authors would like to thank Anna Johansson PT at Sahlgrenska University Hospital for conducting the interviews and the persons with RA who participated in this study for giving their time and sharing their experiences.

Contributors CF and KM conceived the research idea and study design. CF recruited participants, transcribed the interviews and conducted the initial deriving of meaning units. Both CF and KM conducted the analysis. CF conducted an initial draft of the manuscript. Both CF and KM commented and edited the manuscript, and approved the final version of the manuscript.

Funding This work was supported by the University of Gothenburg Centre for Person-Centred Care (www.gpcc.gu.se), The Healthcare Board, Region Västra Götaland (Hälso- och sjukvårdsstyrelsen), and Wilhelm and Martina Lundgrens vetenskapsfond.

Competing interests None declared.

Patient consent for publication Not required.

Ethics approval The study was approved by the Regional Ethics Review Board in Gothenburg, Sweden (ref: 571-16).

Provenance and peer review Not commissioned; externally peer reviewed. Data sharing statement No data are available.

Open access This is an open access article distributed in accordance with the Creative Commons Attribution Non Commercial (CC BY-NC 4.0) license, which permits others to distribute, remix, adapt, build upon this work non-commercially, and license their derivative works on different terms, provided the original work is properly cited, appropriate credit is given, any changes made indicated, and the use is non-commercial. See: http://creativecommons.org/licenses/by-nc/4.0/.

\section{REFERENCES}

1. Kirwan JR, Minnock P, Adebajo A, et al. Patient perspective: fatigue as a recommended patient centered outcome measure in rheumatoid arthritis. J Rheumatol 2007;34:1174-7.

2. Klareskog L, Catrina Al, Paget S. Rheumatoid arthritis. Lancet 2009;373:659-72.

3. Repping-Wuts H, Fransen J, van Achterberg T, et al. Persistent severe fatigue in patients with rheumatoid arthritis. J Clin Nurs 2007;16:377-83.

4. Katz P. Fatigue in Rheumatoid Arthritis. Curr Rheumatol Rep 2017;19:25.

5. Chauffier K, Salliot C, Berenbaum F, et al. Effect of biotherapies on fatigue in rheumatoid arthritis: a systematic review of the literature and meta-analysis. Rheumatology 2012;51:60-8.

6. Nikolaus S, Bode C, Taal E, et al. Fatigue and factors related to fatigue in rheumatoid arthritis: a systematic review. Arthritis Care Res 2013;65:1128-46.

7. Katz P. Causes and consequences of fatigue in rheumatoid arthritis. Curr Opin Rheumatol 2017;29:269-76.

8. Hewlett S, Cockshott Z, Byron M, et al. Patients' perceptions of fatigue in rheumatoid arthritis: overwhelming, uncontrollable, ignored. Arthritis Rheum 2005;53:697-702.

9. Feldthusen $\mathrm{C}$, Björk M, Forsblad-d'Elia $\mathrm{H}$, et al. Perception, consequences, communication, and strategies for handling fatigue in persons with rheumatoid arthritis of working age--a focus group study. Clin Rheumatol 2013;32:557-66.

10. Repping-Wuts $H$, Uitterhoeve $R$, van Riel $P$, et al. Fatigue as experienced by patients with rheumatoid arthritis (RA): a qualitative study. Int J Nurs Stud 2008;45:995-1002.

11. Veldhuijzen van Zanten JJ, Rouse PC, Hale ED, et al. Perceived Barriers, Facilitators and Benefits for Regular Physical Activity and Exercise in Patients with Rheumatoid Arthritis: A Review of the Literature. Sports Med 2015;45:1401-12.

12. Cramp F, Hewlett S, Almeida C, et al. Non-pharmacological interventions for fatigue in rheumatoid arthritis. Cochrane Database Syst Rev 2013;8:CD008322.

13. Thomsen T, Beyer N, Aadahl M, et al. Sedentary behaviour in patients with rheumatoid arthritis: A qualitative study. Int J Qual Stud Health Well-being 2015;10.

14. Verhoeven F, Tordi N, Prati C, et al. Physical activity in patients with rheumatoid arthritis. Joint Bone Spine 2016;83:265-70.

15. Swärdh E, Brodin N. Effects of aerobic and muscle strengthening exercise in adults with rheumatoid arthritis: a narrative review summarising a chapter in Physical activity in the prevention and treatment of disease (FYSS 2016). Br J Sports Med 2016;50:362-7.

16. Cooney JK, Law RJ, Matschke V, et al. Benefits of exercise in rheumatoid arthritis. J Aging Res 2011;2011:681640. 
17. Demmelmaier I, Lindkvist $\AA$, Nordgren B, et al. "A gift from heaven" or "This was not for me". A mixed methods approach to describe experiences of participation in an outsourced physical activity program for persons with rheumatoid arthritis. Clin Rheumatol 2015;34:429-39.

18. Smith BJ, Bauman AE, Bull FC, et al. Promoting physical activity in general practice: a controlled trial of written advice and information materials. Br J Sports Med 2000;34:262-7.

19. Ekman I, Swedberg K, Taft C, et al. Person-centered care--ready for prime time. Eur J Cardiovasc Nurs 2011;10:248-51.

20. Feldthusen C, Dean E, Forsblad-d'Elia H, et al. Effects of PersonCentered Physical Therapy on Fatigue-Related Variables in Persons With Rheumatoid Arthritis: A Randomized Controlled Trial. Arch Phys Med Rehabil 2016;97:26-36.

21. Leplege A, Gzil F, Cammelli M, et al. Person-centredness: conceptual and historical perspectives. Disabil Rehabil 2007;29(20-21):1555-65.

22. McCormack B. Person-centredness in gerontological nursing: an overview of the literature. J Clin Nurs 2004;13(3a):31-8.

23. Olsson LE, Jakobsson Ung E, Swedberg K, et al. Efficacy of personcentred care as an intervention in controlled trials - a systematic review. J Clin Nurs 2013;22(3-4):456-65.

24. Smith C. What is a person?: Rethinking humanity, social life, and the moral good from the person up. Chicago and London: University of Chicago Press, 2010.

25. Dicicco-Bloom B, Crabtree BF. The qualitative research interview. Med Educ 2006; 40:314-21.

26. Krippendorff K. Content analysis: an introduction to its methodology. Thousand Oaks, Calif: Sage, 2004.

27. Elo S, Kyngäs $\mathrm{H}$. The qualitative content analysis process. J Adv Nurs 2008;62:107-15.

28. Aletaha D, Neogi T, Silman AJ, et al. 2010 Rheumatoid arthritis classification criteria: an American College of Rheumatology/ European League Against Rheumatism collaborative initiative. Arthritis Rheum 2010;62:2569-81.

29. Arnett FC, Edworthy SM, Bloch DA, et al. The American Rheumatism Association 1987 revised criteria for the classification of rheumatoid arthritis. Arthritis Rheum 1988;31:315-24.

30. Graneheim UH, Lundman B. Qualitative content analysis in nursing research: concepts, procedures and measures to achieve trustworthiness. Nurse Educ Today 2004;24:105-12.

31. Graneheim UH, Lindgren BM, Lundman B. Methodological challenges in qualitative content analysis: A discussion paper. Nurse Educ Today 2017;56:29-34.
32. Hewlett S, Dures E, Almeida C. Measures of fatigue: Bristol Rheumatoid Arthritis Fatigue Multi-Dimensional Questionnaire (BRAF MDQ), Bristol Rheumatoid Arthritis Fatigue Numerical Rating Scales (BRAF NRS) for severity, effect, and coping, Chalder Fatigue Questionnaire (CFQ), Checklist Individual Strength (CIS20R and CIS8R), Fatigue Severity Scale (FSS), Functional Assessment Chronic Illness Therapy (Fatigue) (FACIT-F), Multi-Dimensional Assessment of Fatigue (MAF), Multi-Dimensional Fatigue Inventory (MFI), Pediatric Quality Of Life (PedsQL) Multi-Dimensional Fatigue Scale, Profile of Fatigue (ProF), Short Form 36 Vitality Subscale (SF-36 VT), and Visual Analog Scales (VAS). Arthritis Care Res 2011;63(Suppl 11):S263-86.

33. Mannerkorpi K, Hernelid C. Leisure Time Physical Activity Instrument and Physical Activity at Home and Work Instrument. Development, face validity, construct validity and test-retest reliability for subjects with fibromyalgia. Disabil Rehabil 2005;27:695-701.

34. Swärdh E, Biguet G, Opava CH. Views on exercise maintenance: variations among patients with rheumatoid arthritis. Phys Ther 2008;88:1049-60.

35. Brehm JW, Self EA. The intensity of motivation. Annu Rev Psychol 1989:40:109-31.

36. Weman Josefsson K. Mechanisms in Self-Determined Exercise Motivation. A PhD Thesis Summary. International Journal Of Women \& Apos 2016;2

37. Wilcox S, Der Ananian C, Abbott J, et al. Perceived exercise barriers, enablers, and benefits among exercising and nonexercising adults with arthritis: results from a qualitative study. Arthritis Rheum 2006;55:616-27.

38. Brodin N, Eurenius E, Jensen I, et al. Coaching patients with early rheumatoid arthritis to healthy physical activity: a multicenter, randomized, controlled study. Arthritis Rheum 2008;59:325-31.

39. Sjöquist ES, Brodin N, Lampa J, et al. Physical activity coaching of patients with rheumatoid arthritis in everyday practice: a long-term follow-up. Musculoskeletal Care 2011:9:75-85.

40. Michie S, Fixsen D, Grimshaw JM, et al. Specifying and reporting complex behaviour change interventions: the need for a scientific method. Implement Sci 2009;4:40.

41. Lange E, Kucharski D, Svedlund S, et al. Effects of Aerobic and Resistance Exercise in Older Adults With Rheumatoid Arthritis: A Randomized Controlled Trial. Arthritis Care Res 2019;71:61-70.

42. Larsson A, Palstam A, Löfgren M, et al. Resistance exercise improves muscle strength, health status and pain intensity in fibromyalgia--a randomized controlled trial. Arthritis Res Ther 2015;17:161. 